\begin{tabular}{|l|l|l|l|l|l|l|}
\hline InterteXto & Uberaba & UFTM & $\begin{array}{l}\text { v. 3 } \\
\text { n. 1 }\end{array}$ & p. 61-84 & 2010 - jan. / jun. & ISSN 1981-0601 \\
\hline
\end{tabular}

\title{
A CONCEPÇÃO DE GÊNERO NA LINGUÍSTICA TEXTUAL: CONTRIBUIÇÕES DA ESCOLA NORTE-AMERICANA
}

\section{THE CONCEPTION OF GENRES IN THE TEXTUAL LINGUISTIC: CONTRIBUTIONS OF THE NORTH AMERICAN SCHOOL}

\author{
Albeiro Mejia Trujillo ${ }^{1}$ \\ Maria Francisca Ferreira Trujillo ${ }^{2}$
}

\begin{abstract}
Resumo: No presente artigo apresenta-se uma breve contextualização das principais escolas de "Gêneros Discursivos" na Linguística Textual. Num primeiro momento destaca-se a importância da teoria bakhtiniana de gêneros para o desenvolvimento das escolas americana, australiana, de Genebra, e a francesa, fazendo um recorte temático pela escola norte-americana. Dentro dessa escola destaca-se a Nova Retórica na perspectiva de Carolyn Miller que trabalha a noção de gênero como "ação social"; Charles Bazerman que aborda os gêneros como instrumento de interação em contextos institucionais; a escola swalesiana da qual fazem parte Swales com a sua noção de "comunidade discursiva", e o indiano Bhatia que direciona a análise do discurso para o estudo dos gêneros "no contexto profissional e acadêmico". O texto aqui exposto, embora tenha como foco a Escola norte-americana inclui algumas contribuições do principal expoente dessa temática, no Brasil, que é Luiz Antônio Marcuschi que, entre outros elementos, estabelece a distinção entre gênero textual e tipo textual. Finalizando o artigo, é proposta uma discussão sobre a pertinência dos gêneros discursivos, na Linguística Textual, em face dos conceitos de gênero na Teoria da Literatura.
\end{abstract}

Palavras-chave: gêneros textuais; tipos textuais; comunidade discursiva; esfera social; enunciado.

Abstract: This article presents a brief context of the main schools of "Discursive Genres" in the Textual Linguistic. First, it is explored the importance of the Bakhtin theory of genres for the development of the schools in American, Australia, Geneva and France, distinguishing a thematic clipping for the North American school. Inside this school it is distinguished the New Rhetoric in the perspective of Carolyn Miller who sees the genre notion as "social action"; Charles Bazerman who approaches the genre as instrument of interaction in institutional contexts; the Swales school with its notion of "discursive community", and the Indian author, Bhatia, which directs the speech analysis for the study of the genres "in the professional and academic contexts". The text, even so has as focus the North American Schoolm, includes some contributions of the main exponent of this thematic in Brazil, that is Luiz Antonio Marcuschi who,

\footnotetext{
${ }^{1}$ Formado em Filosofia e em Letras, Mestre em Teoria da Literatura e Doutor em Literatura pela Universidade de Brasília. malbeiro@yahoo.com.br

${ }^{2}$ Formada em Letras, Mestra em Educação pela Universidade Católica de Brasília e

Doutoranda em Língua Portuguesa pela PUC/SP. mariatrujillo@mec.gov.br
} 


\begin{tabular}{|l|l|l|l|l|l|l|}
\hline InterteXto & Uberaba & UFTM & $\begin{array}{l}\text { v. 3 } \\
\text { n. } 1\end{array}$ & p. 61-84 & 2010 - jan. / jun. & ISSN 1981-0601 \\
\hline
\end{tabular}

among others elements, establishes the distinction between textual genre and textual type. To conclude, it is proposed a discussion about the relevancy of the discursive genres, in Textual Linguistic, considering the concepts of genre in the Theory of Literature.

Key-words: textual genres; textual types; discursive community; social sphere; enunciation.

\section{Introdução}

Do ponto de vista da estética, afirmar que o texto literário desafia a racionalidade incorporada nos discursos institucionalizados nos conduz à retomada da questão dos gêneros literários. A emergência em abordar este tema, aparentemente superado nos estudos literários deve-se ao surgimento, a partir da segunda metade do século $X X$, da discussão sobre os Gêneros do Discurso, na Linguística Textual, e consequente profusão de publicações nesse campo de estudos. Na década de sessenta do século $X X$, surge a corrente americana denominada de "Nova Retórica" e, na França, no mesmo período, começam a ser desenvolvidos estudos aplicados sobre gêneros discursivos. Entre os autores de maior destaque no mundo em tal área temos: M. Bakhtin, V. K. Bhatia, Charles Bazerman, J. Bronckart, Carolyn Miller, Gunther Kress, John Swales, Jean-Michel Adam e, no Brasil, um dos maiores divulgadores dessa temática tem sido Luiz Antônio Marcuschi.

Os estudos sobre gêneros discursivos vêem despertando o interesse de muitos pesquisadores em todo o mundo e, embora apresentem abordagens diferentes, dependendo da "escola": sendo as mais representativas a norteamericana, a australiana (Sidney), a de Genebra e a bakhtiniana (Russa), todas elas apresentam uma característica comum que é o reconhecimento da importância em considerar o "social" e o papel do "contexto" discursivo para poder compreender os gêneros em suas múltiplas manifestações.

Enquanto as abordagens tradicionais de gêneros tinham como foco a relação língua/linguagem apoiadas nos paradigmas da Gramática Tradicional; 


\begin{tabular}{|l|l|l|l|l|l|l|}
\hline InterteXto & Uberaba & UFTM & $\begin{array}{l}\text { v. 3 } \\
\text { n. } 1\end{array}$ & p. 61-84 & 2010 - jan. / jun. & ISSN 1981-0601 \\
\hline
\end{tabular}

e nas abordagens estruturalistas, que tiveram o seu mérito em um determinado tempo e contexto histórico, a questão atual dos gêneros, e sua distinção tipológica tornou-se um desafio para os estudiosos da língua, pois os critérios para análise são controversos e difusos.

Para Ramires (2005), uma primeira consideração a se fazer sobre gêneros é a de terem estes um caráter sociocomunicativo, serem situados concretamente em contextos sociais de uso, regulados por normas definidas pelas diversas comunidades de diferentes culturas, cujas atividades são representadas na linguagem. Outra consideração importante, decorrente dessa primeira, é que, sem se descuidar totalmente de seus aspectos formais ou estruturais, o seu estudo enfatiza as propriedades sociocognitivas, ou seja, suas propriedades funcionais. É assim que, na análise de gêneros, enfocamse, principalmente, os componentes sociais, históricos, culturais e cognitivos, que lhes dão concretude e os determinam.

\section{Importância da teoria de gêneros de Bakhtin}

Bakhtin tem como base dos estudos de gênero a interação verbal e o dialogismo interacional. Os seus estudos influenciaram a Escola de Genebra e a Escola Norte-Americana de estudos de gênero. Para Bakhtin (1997) as esferas $^{3}$ da atividade humana estão relacionadas com a utilização da língua e os modos de utilização, sendo que as esferas variam dentro de uma unidade lingüística. A utilização oral e escrita da língua acontece por meio de enunciados os quais refletem as condições específicas e as finalidades de cada uma dessas esferas. O enunciado é formado por três elementos: conteúdo temático, estilo e construção composicional. Eles se caracterizam pela especificidade de uma determinada esfera da comunicação, cada esfera de utilização da língua elabora seus tipos de enunciados, os quais são

\footnotetext{
${ }^{3}$ Autores como Bourdieu, Habermas, Gramsci, Arendt, etc., utilizam o conceito de "esfera" para se referirem a domínios específicos de ação social. Falta nas referências bakhtinianas uma indicação da abrangência e sentido atribuído à noção de "esfera" quando associada ao campo dos Gêneros Discursivos.
} 


\begin{tabular}{|l|l|l|l|l|l|l|}
\hline InterteXto & Uberaba & UFTM & $\begin{array}{l}\text { v. 3 } \\
\text { n. } 1\end{array}$ & p. 61-84 & 2010 - jan. / jun. & ISSN 1981-0601 \\
\hline
\end{tabular}

relativamente estáveis e são denominados gêneros do discurso.

Evidentemente, cada enunciado particular é individual, mas cada campo de utilização da língua elabora seus tipos relativamente estáveis de enunciados, os quais denominamos gêneros do discurso (BAKHTIN, 2003, p. 262).

Os gêneros do discurso são ricos, variados e infinitos, pois estão relacionados à atividade humana e a mesma é inesgotável. Cada esfera de atividade possui um repertório de gêneros que se amplia e difere de acordo com a complexidade da esfera social. Bakhtin (1997) aponta exemplos de diferentes tipos de gêneros do discurso e afirma que os estudos nessa área se preocuparam com os gêneros literários e esqueceram de outros tipos de enunciados. A lingüística geral, segundo o autor, não se preocupava com a natureza do enunciado e por essa razão houve dificuldade em reconhecer a heterogeneidade dos gêneros do discurso. Para ele é muito importante perceber a diferença entre o gênero do discurso primário e o secundário.

Não se deve, de modo algum, minimizar a extrema heterogeneidade dos gêneros discursivos e a dificuldade daí advinda de definir a natureza geral do enunciado. Aqui é de especial importância atentar para a diferença essencial entre os gêneros discursivos primários (simples) e secundários (complexos) - não se trata de uma diferença funcional. Os gêneros discursivos secundários (complexos - romances, dramas, pesquisas científicas de toda espécie, os grandes gêneros publicísticos, etc.) surgem nas condições de um convívio cultural mais complexo e relativamente muito desenvolvido e organizado (predominantemente escrito) artístico, científico, sociopolítico, etc. (BAKHTIN, 2003, p. 263).

O autor destaca os elementos necessários no estudo dos gêneros: a interrelação entre os gêneros primários (simples) e secundários (complexos), e o processo histórico de formação dos gêneros secundários. Esses elementos ajudam a esclarecer a natureza do enunciado (correlação entre língua, ideologias e visões do mundo). Bakhtin (1997) defende a importância do estudo da natureza do enunciado e da diversidade dos gêneros de enunciados nos 


\begin{tabular}{|l|l|l|l|l|l|l|}
\hline InterteXto & Uberaba & UFTM & $\begin{array}{l}\text { v. 3 } \\
\text { n. } 1\end{array}$ & p. 61-84 & 2010 - jan. / jun. & ISSN 1981-0601 \\
\hline
\end{tabular}

diferentes campos de atuação da atividade humana, principalmente pela lingüística e ciências correlatas como a filologia. O autor afirma que o estudo concreto da linguagem ${ }^{4}$ se dá por meio do estudo da natureza do enunciado e das particularidades de gênero dentro do discurso. Para ele o enunciado é individual (é nele que a língua se encarna como forma individual), mas nem todos os gêneros refletem a individualidade de quem escreve e fala. Para exemplificar, o autor cita os gêneros do discurso que possuem forma padronizada (documentos burocráticos).

Cabe salientar em especial a extrema heterogeneidade dos gêneros do discurso (orais e escritos), nos quais devemos incluir as breves réplicas do diálogo do cotidiano (salienta-se que a diversidade das modalidades de diálogo cotidiano é extraordinariamente grande em função do seu tema, da situação e da composição dos participantes), o relato do dia-adia, a carta (em todas as suas diversas formas), o comando militar lacônico padronizado, a ordem desdobrada e detalhada, o repertório bastante vário (padronizado na maioria dos casos) dos documentos oficiais e o diversificado universo das manifestações publicísticas (no amplo sentido do termo: sociais, políticas); mas aí também devemos incluir as variadas formas das manifestações científicas e todos os gêneros literários (do provérbio ao romance de muitos volumes) (BAKHTIN, 2003, p. 262).

O autor defende a importância do estudo do estilo na análise do gênero e demonstra que cada função e determinadas condições, dentro de cada uma das esferas da comunicação verbal, originam um determinado gênero relativamente estável (do ponto de vista do tema, composição e estilo); portanto, não se pode separar o estilo do gênero. Segundo as concepções de Bakhtin (1997, p. 308): a língua está em todas as esferas da atividade humana; a língua se concretiza em forma de enunciados (orais e escritos); os gêneros do discurso são infinitos e heterogêneos; existem os gêneros primários

\footnotetext{
${ }^{4}$ Sabe-se que a linguagem abrange todas as formas de expressão humana, e que a língua é tão somente uma das manifestações da linguagem. Se, como afirma Bakhtin, o estudo concreto da linguagem se dá pelo estudo da natureza do enunciado, devemos nos perguntar qual é a delimitação do conceito de "enunciado" para dirimir a dúvida se o autor russo está a se referir a linguagem ou somente aos usos da língua nas suas expressões verbal e escrita.
} 


\begin{tabular}{|l|l|l|l|l|l|l|}
\hline InterteXto & Uberaba & UFTM & $\begin{array}{l}\text { v. 3 } \\
\text { n. } 1\end{array}$ & p. 61-84 & 2010 - jan. / jun. & ISSN 1981-0601 \\
\hline
\end{tabular}

(simples), e os secundários (complexos, isto é, que estão relacionados à comunicação cultural mais evoluída da sociedade); a unidade real da comunicação verbal é o enunciado; o discurso se molda sempre à forma do enunciado que pertence a um sujeito falante e não pode existir fora dessa forma; aprender a falar é aprender a estrutura dos enunciados; o enunciado é um elo na cadeia da comunicação verbal que representa a instância ativa do locutor numa ou noutra esfera do objeto do sentido e se caracteriza pelo conteúdo preciso do objeto do sentido.

\section{Algumas contribuições da Escola Norte-Americana para os estudos sobre gênero.}

\subsection{Estudos norte-americanos de gênero}

A escola norte-americana de estudos sobre gêneros textuais tem o foco voltado para a observação das implicações que os fatores sociais, culturais e institucionais têm sobre a produção de diferentes gêneros e, por outro lado, de que forma a criação/produção textual interfere nas relações sociais das atividades humanas.

\subsubsection{Principais representantes da escola norte-americana - Nova Retórica - Carolyn Miller: gênero como ação social}

Miller desenvolveu suas pesquisas sobre gêneros nas décadas de 80 e 90 do século XX. A tentativa da autora foi articular a compreensão de gêneros aos processos sociais e aos usos que se faz da linguagem. Para Miller, a criação de certos textos, a interpretação e os modelos hierárquicos de comunicação esclarecem a natureza e estrutura de determinada ação retórica; nesse prisma, o conceito de gênero passa a ser entendido como ação social, dentro de um contexto de situação e interação comunicativa.

A autora analisa o problema da definição de gêneros. Para ela os gêneros retóricos são definidos pelas semelhanças que eles possuem nas estratégias utilizadas ou nas formas como são apresentados no discurso. Essas 


\begin{tabular}{|l|l|l|l|l|l|l|}
\hline InterteXto & Uberaba & UFTM & $\begin{array}{l}\text { v. 3 } \\
\text { n. } 1\end{array}$ & p. 61-84 & 2010 - jan. / jun. & ISSN 1981-0601 \\
\hline
\end{tabular}

semelhanças podem estar focalizadas em: o público, os modos de pensamento, situações semelhantes e retóricas. Para Miller o termo "gênero" deve significar algo teórico ou criticamente útil, o qual não pode referir-se somente a qualquer categoria ou espécie do discurso.

O ensaio que Miller escreveu se divide em dois pontos importantes. Primeiramente ela apresenta reflexões sobre as definições de gêneros e em seguida procura demonstrar como as pessoas encontram, interpretam, reagem e criam determinados textos. A autora acredita que o estudo de Gênero é valioso porque acentua alguns aspectos sociais e históricos da retórica que outras perspectivas não fazem. Para ela a definição retoricamente sólida do gênero deve ser centrada na ação que é usada para realizar o discurso e não na substância ou forma do mesmo.

Miller (1984) observa que os modelos hierárquicos da comunicação podem ajudar a esclarecer a natureza e a estrutura da ação retórica. Nessa perspectiva uma classificação do discurso será retoricamente sólida se ele contribuir para uma compreensão de como o discurso trabalha e se ele reflete a experiência retórica das pessoas que criam e interpretam o discurso. A autora afirma que a Semiótica utiliza um modo de caracterizar os princípios usados para classificar o discurso, de acordo com o princípio que o rege: princípio da definição (semântica); princípio da forma (sintaxe); princípio da ação (pragmática).

A autora analisa estudos de diferentes teóricos que definem e classificam gêneros retóricos, no entanto, a classificação que ela defende é etnometodológica, a qual procura explicar o conhecimento que a prática cria. Isto implica afirmar que os gêneros utilizados na linguagem cotidiana dizem algo importante sobre o discurso. Para considerar como gêneros potenciais o discurso simples, não se deve banalizar o estudo de gêneros; o que deve ser feito é levar a retórica a sério e considerar as situações em que são produzidos esses discursos.

Outro questionamento que é apresentado por Miller recai sobre a situação 


\begin{tabular}{|l|l|l|l|l|l|l|}
\hline InterteXto & Uberaba & UFTM & $\begin{array}{l}\text { v. 3 } \\
\text { n. } 1\end{array}$ & p. 61-84 & 2010 - jan. / jun. & ISSN 1981-0601 \\
\hline
\end{tabular}

retórica, afinal ela é material e objetiva ou é um construto social? E como compreender a exigência que está no núcleo da situação? A exigência é uma forma de consciência mútua de objetos, eventos, interesses e objetivos que a torna uma necessidade social. A situação retórica prevê o retorno de um modo socialmente reconhecível de fazer as suas intenções conhecidas, e não deve ser vista nem como uma causa da ação retórica nem como intenção, mas unicamente como motivo social.

Miller (1984) defende a classificação do discurso tendo como base uma situação periódica ou, mais especificamente, a exigência entendida como motivo social, o que significa baseá-lo nas ações retóricas conjuntas disponíveis em um determinado período histórico e cultural. Miller apresenta, também, o modelo hierárquico de comunicação proposto por W. Barnett Pearce e Forrest Conklin composto de cinco níveis: os arquétipos que são operações lógicas fundamentais ou procedimentos racionais simbólicos que as pessoas usam para descobrir ou gerar modelos na sequência de eventos; os episódios que são as sequências das mensagens que têm um começo, um meio e uma estrutura interna; os atos de discurso que são sequências padronizadas que fornecem o contexto de atos de discurso; e os dois níveis hierárquicos de proposição os quais apontam que a corrente do comportamento são unidos por conjuntos de regras que coordenam o movimento cognitivo entre eles.

Para Miller (1984) as implicações que a compreensão de gênero retórico tem são baseadas na prática retórica, nas convenções do discurso que uma sociedade estabelece como caminhos da ação em conjunto. O gênero retórico não é classificável, desenvolve-se e desaparece, o número de correntes desse gênero em qualquer sociedade é indeterminado e depende da complexidade e da diversidade da sociedade. As características que determinam esse tipo de gênero são:

1. refere-se a uma categoria convencional do discurso, baseado em tipificação da ação retórica;

2. é interpretável por meio de regras; 


\begin{tabular}{|l|l|l|l|l|l|l|}
\hline InterteXto & Uberaba & UFTM & $\begin{array}{l}\text { v. 3 } \\
\text { n. } 1\end{array}$ & p. 61-84 & 2010 - jan. / jun. & ISSN 1981-0601 \\
\hline
\end{tabular}

3. é distinto da forma;

4. serve-se da substância de formas para desenvolver os níveis mais altos;

5. é um meio retórico para mediar intenções privadas e exigência social.

Miller (1984) deixa claro que um gênero personifica um aspecto da racionalidade cultural e que para o crítico, os gêneros tanto podem servir como um índice de modelos culturais como instrumentos para explorar as realizações de determinados falantes e escritores. Para o estudante, os gêneros servem de chaves à compreensão da participação nas ações de uma comunidade.

\subsubsection{Charles Bazerman: gêneros como interação}

Bazerman (2004) afirma que os instrumentos conceituais e analíticos são necessários na análise dos textos produzidos na sociedade. A produção de textos envolve diversos fatos sociais que são produzidos, e que não existiriam se as pessoas não os realizassem por meio da criação de textos; portanto, há um ciclo de atividades chamadas de sistemas organizacionais onde os fatos são representados nos textos e os textos são geradores de outras ações sociais.

As tipificações de situações, intenções e objetivos, modos de ação e gêneros textuais que o escritor aplica à situação criam uma espécie de habitat para o escritor habitar psicológica e socialmente. Isto é, tipificações dão aos escritores meios simbólicos para fazer sentido das coisas. Por sua vez, esses meios de fazer sentido ajudam a estabelecer o palco e o enquadre para a possível ação (BAZERMAN, 2007, p. 58-59).

Bazerman (2004) deixa claro que o entendimento dos gêneros textuais e seu funcionamento é importante na produção de diferentes tipos de textos compreensíveis e para isso é necessário rever alguns conceitos básicos como fatos sociais e situação. O autor define como fatos sociais as coisas que as pessoas acreditam que sejam verdadeiras e essa crença afeta o modo como as pessoas definem uma situação, a partir dessa definição elas agem como se 


\begin{tabular}{|l|l|l|l|l|l|l|}
\hline InterteXto & Uberaba & UFTM & $\begin{array}{l}\text { v. 3 } \\
\text { n. } 1\end{array}$ & p. 61-84 & 2010 - jan. / jun. & ISSN 1981-0601 \\
\hline
\end{tabular}

os fatos fossem verdades. Os fatos sociais influenciam os discursos produzidos pelas pessoas e esses possuem força, pois muitos deles dependem de atos de fala e quando realizados de forma apropriada, as palavras serão consideradas como atos feitos.

\begin{abstract}
Uma maneira de perceber a relação entre um texto e as suas conseqüências é considerar o texto como um ato de fala. Para 0 ato ter sucesso, ele deve satisfazer certas condições relevantes para ambos, o gênero no qual é compreendido como um exemplar e as situações localizadas onde o gênero é (re)encenado (BAZERMAN, 2007, p. 65).
\end{abstract}

Bazerman cita o filósofo John Austin o qual defende o poder transformador das palavras ao afirmar que elas não apenas têm um significado na sociedade, mas transformam a vida das pessoas. Dentro dessa leitura podemos mencionar o livro do Gênese, na Bíblia, ao relatar a criação do universo quando Deus utiliza a "Palavra" para criar tudo o que existe no universo.

Para Austin todo enunciado, na sociedade, traz em si atos de fala. Austin e John Searle afirmam que os atos de fala operam em três níveis: ato locucionário: aquilo que é dito; ato proposicional: ato decorrente do que é dito; ato ilocucionário: ato que será reconhecido pelo ouvinte. É importante observar que o modo como as pessoas recebem os atos e se manifestam em relação a esse fato linguístico é chamado de efeito perlocucionário. Esse tipo de análise (três níveis dos atos da fala) aplica-se também a textos escritos.

Charles Bazerman (2004) afirma que as intenções nos atos de fala podem ser mal compreendidas e comprometem a coordenação das idéias para expressar clareza nos atos de fala e essa dificuldade aumenta ainda mais nos textos escritos. O autor mostra que, com a experiência de comunicação, é possível as pessoas irem criando padrões os quais são reforçados e se estabilizam como gêneros. A tipificação são as formas de enunciados padronizados que estão relacionados às circunstâncias das ações sociais.

O próprio autor afirma ser a definição de gênero que ele defende, 


\begin{tabular}{|l|l|l|l|l|l|l|}
\hline InterteXto & Uberaba & UFTM & $\begin{array}{l}\text { v. 3 } \\
\text { n. } 1\end{array}$ & p. 61-84 & 2010 - jan. / jun. & ISSN 1981-0601 \\
\hline
\end{tabular}

diferente da noção que estamos habituados a usar. Para ele é um fenômeno de reconhecimento psicossocial e que faz parte de atividades socialmente organizadas, surge nos processos sociais e vai além da forma textual. A definição do autor está mais relacionada com a função social do gênero e não com a forma, portanto, gênero, para Bazerman é a coleção de tipos de textos que uma pessoa num determinado papel tende a produzir; e um sistema de gêneros compreende os diversos conjuntos de gêneros utilizados, por exemplo, pelos funcionários de uma empresa. E esse sistema de atividades tem como centro de interesse a produção escrita.

Em textos como contratos, formulários e pedidos comerciais, é
mais claramente visto que documentos criam fatos sociais. Em
tais casos o texto fornece a base para outras ações (e.g.,
entrevistas para emprego serão agendadas e produtos serão
mandados) e responsabiliza as pessoas que se
comprometeram nos textos (e.g., que eu terminarei o trabalho
contratado ou que aceitarei receber o produto pedido).
Contudo, declarações menos obviamente comportamentais
podem ser vistas como atos e fatos sociais conseqüentes
(BAZERMAN, 2007, p. 168).

Segundo Bazerman, no dia-a-dia nos deparamos com um problema que é a identificação e compreensão dos gêneros e atos de fala dos textos escritos, o que se fará possível através da pesquisa e o estudo desses processos. Para ele os gêneros possuem características comuns que ajudam a reconhecer a espécie de texto e essas características estão relacionadas com as funções ou atividades realizadas pelo gênero. Para isso o autor levanta quatro pontos que demonstram a dificuldade em identificar e analisar gêneros: as pessoas recebem cada texto de forma diferente; há variação de um mesmo exemplar de um gênero e a visão de gênero, enquanto coleção de elementos característicos, também pode variar.

Cada novo texto vale-se da história de enunciados dos quais o gênero emerge e se sustenta, de modo que os textos podem ser identificados e entendidos dentro de uma tradição de enunciados daquele tipo ou gênero (BAZERMAN, 2007, p. 


\begin{tabular}{|l|l|l|l|l|l|l|}
\hline InterteXto & Uberaba & UFTM & $\begin{array}{l}\text { v. 3 } \\
\text { n. } 1\end{array}$ & p. 61-84 & 2010 - jan. / jun. & ISSN 1981-0601 \\
\hline
\end{tabular}

173).

Além dessas questões, Bazerman (2004) apresenta algumas sugestões que ajudam a identificar e analisar gêneros: utilizar vários conceitos analíticos lingüísticos, retóricos ou organizacionais na análise dos textos; considerar as variações de textos ou "o mesmo gênero" em diferentes áreas ou campos; pesquisar sobre os gêneros não conhecidos; fazer pesquisas etnográficas sobre os gêneros usados pelas pessoas.

\subsubsection{John M. Swales: propósitos comunicativos}

Swales (1990) analisa as origens e influências da abordagem de gêneros ligadas a trabalhos anteriores, tanto no campo da Linguística Aplicada quanto na da não-Aplicada e apresenta uma síntese dessas influências. Abordagem situacional: surgiu nos anos 60 e tem como principal representante Neile Osman (1959 apud Swales, 1990) cujo estudo foi realizado com imigrantes australianos nos Estados Unidos. Essa influência prevê o uso de pesquisa de estratégias e habilidades em situações específicas; abordagem teórico/funcional: influenciou significativamente o trabalho de Swales, devido ao comprometimento natural com os propósitos comunicativos e com as

necessidades do aprendiz. O ponto negativo dessa abordagem é a simplificação exagerada que o autor faz das sentenças e os discursos realizados em ambientes profissionais.

O autor recebeu muita influência da análise do discurso, utilizou a sua experiência de professor para deduzir que os alunos têm um melhor desempenho ao desenvolver os assuntos comunicativos quando se concentram nas características sui generis do gênero textual em particular. Swales (1990) enfatiza que os gêneros são considerados algo a mais do que textos e para ele a análise textual permanece de modo insuficiente para descrever gêneros de forma completa, isto porque a análise textual não explica porque os gêneros assumiram certas características com o passar do tempo. 


\begin{tabular}{|l|l|l|l|l|l|l|}
\hline InterteXto & Uberaba & UFTM & $\begin{array}{l}\text { v. 3 } \\
\text { n. } 1\end{array}$ & p. 61-84 & 2010 - jan. / jun. & ISSN 1981-0601 \\
\hline
\end{tabular}

Para ele o que determina o gênero são as comunidades discursivas, as quais se familiarizam com gêneros específicos e os utilizam para alcançar seus objetivos. Logo, os gêneros pertencem à comunidade e não a indivíduos.

E o que é comunidade discursiva? O autor mostra que o conceito ainda é bastante polêmico e não está bem definido. Swales (1990) afirma ser a expressão utilizada por estudiosos que possuem uma visão mais social do processo da escrita e que veem o conceito comunidade discursiva como poderoso e útil, mesmo sem ter uma resposta definitiva para as inúmeras perguntas que surgem a esse respeito.

Existem outros elementos que Swales aponta como merecedores de atenção na conceituação de comunidade discursiva: nem toda comunidade é necessariamente discursiva e nem toda atividade discursiva é importante na formação de uma comunidade discursiva. Para isso é importante distinguir os grupos sociolinguísticos (aqueles que possuem comportamentos linguísticos sociais) e os sociorretóricos (aqueles que possuem comportamentos linguísticos funcionais).

Swales (1990), ao estudar a estrutura da sociedade, aponta algumas características sociais que servem para identificar uma comunidade discursiva: possui objetivos comuns, como exemplo, aqueles que ocupam cargos políticos; mesmo sem os indivíduos se conhecerem, há práticas de comunicação comum a todos os seus membros, as mensagens que eles produzem e recebem são semelhantes e limitadas (integrantes de missões diplomáticas).

Nessa comunidade os indivíduos trocam correspondências entre si (associações, etc.); são usados um ou mais gêneros em suas comunicações/correspondências, os quais servem para sinalizar os objetivos dessa comunidade; os indivíduos utilizam elementos lexicais particulares e até determinado jargão técnico (médicos, juristas); essa comunidade possui um número mínimo de indivíduos com objetivos comuns, troca de informações e vocabulário especializado, dentre outros. Exemplo: colecionadores de selos.

Swales (1990) analisou os diferentes conceitos de gêneros em outras 


\begin{tabular}{|l|l|l|l|l|l|l|}
\hline InterteXto & Uberaba & UFTM & $\begin{array}{l}\text { v. 3 } \\
\text { n. } 1\end{array}$ & p. 61-84 & 2010 - jan. / jun. & ISSN 1981-0601 \\
\hline
\end{tabular}

áreas do conhecimento como: folclore, literatura, lingüística e retórica. Para o autor, avaliar esses conceitos significa ver o texto dentro de um contexto cultural, histórico e socioeconômico. Ele discute o conceito de gênero apresentado pela Lingüística Sistêmica que diferencia gênero de registro. Para Couture (1986 apud Swales, 1990), gêneros são textos que possuem estruturas completas (relatórios) e registros são os diferentes estilos utilizados na elaboração de um texto (linguagem jurídica, linguagem burocrática).

Swales (1990) aponta, ainda, para aquilo que o folclore, a literatura, a linguística e a retórica possuem em comum em relação aos gêneros. Segundo o autor, as referidas áreas do conhecimento reconhecem uma classificação de gêneros não muito simples; postulam que os gêneros possuem uma dimensão temporal; eles estão inseridos em uma comunidade e representam as crenças e as práticas da mesma; e são objeto de interesse, no que diz respeito a sua estrutura. Segundo o autor, é possível utilizar os gêneros com finalidades pedagógicas, desde que o aluno possa refletir sobre o alcance retórico e linguístico do mesmo.

\subsubsection{BHATIA, V. K.: abordagem de gêneros aplicada}

Bhatia (1993) desenvolve sua teoria sobre gêneros em três segmentos importantes. Primeiro é apresentada a teoria da análise de gêneros que tem como objetivo focar a análise do discurso ao estudar os gêneros profissionais e acadêmicos. E essa análise do discurso apresenta dois aspectos importantes que são: a descrição, centrada nos aspectos linguísticos da construção e da interpretação de texto; e a explanação que procura explicar os aspectos convencionais da construção e interpretação do gênero. $O$ autor utiliza esses dois aspectos para abrir uma discussão sobre a análise do gênero como atividade multidisciplinar e uma abordagem para a análise do discurso profissional e acadêmico.

No segundo momento, ele faz um retrospecto histórico da Análise do Discurso e aponta para quatro níveis de descrição linguística: 


\begin{tabular}{|l|l|l|l|l|l|l|}
\hline InterteXto & Uberaba & UFTM & $\begin{array}{l}\text { v. 3 } \\
\text { n. } 1\end{array}$ & p. 61-84 & 2010 - jan. / jun. & ISSN 1981-0601 \\
\hline
\end{tabular}

1- descrição lingüística de superfície (análise de registro);

2- descrição funcional da linguagem (análise gramáticoretórica);

3- descrição da linguagem como discurso (análise interacional);

4- descrição lingüística como explanação (análise de gênero).

Bhatia (1993) explora o terceiro nível (descrição da linguagem como discurso) e mostra que no centro desse tipo de análise está a interpretação do discurso pelo leitor/ouvinte. Apresenta, também, diferentes nomenclaturas dadas por diferentes autores:

$>$ análise do discurso aplicada Widdwson (1973);

> funções da fala - Candlin et al. (1974 apud Bhatia, 1993);

$>$ análise do discurso interativo - Sinclair \& Couthard (1975);

> análise de estruturas preditivas - Tadros (1981 apud Bhatia, 1993);

$>$ análise em termos - Winter e Hoey (1977 apud Bhatia, 1993).

O autor considera valiosa a contribuição da análise interacional porque ela enfatiza a natureza interativa do discurso e destaca a noção de estrutura no uso da língua, muito embora não tenha dado a atenção necessária às restrições socioculturais, institucionais e organizacionais que envolvem o gênero escrito. Ele defende a necessidade de combinar aspectos socioculturais e psicolinguísticos na descrição de uma língua. Para isso ele cita Swales que segue esse processo de combinação na análise de gênero como descrição dos textos profissionais e acadêmicos.

Bhatia (1993) considera importante observar a relação que há entre a forma dos recursos lingüísticos e os valores funcionais que eles assumem no discurso dentro de uma abordagem de gênero, fato que não se dá com muita nitidez em outra abordagem de variação lingüística. $O$ autor valoriza a contribuição que Swales faz da definição de gêneros, mas critica o fato de Swales desconsiderar os fatores psicológicos na construção de um gênero. Bhatia (1993) vê cada gênero como um propósito comunicativo alcançado. 


\begin{tabular}{|l|l|l|l|l|l|l|}
\hline InterteXto & Uberaba & UFTM & $\begin{array}{l}\text { v. 3 } \\
\text { n. } 1\end{array}$ & p. 61-84 & 2010 - jan. / jun. & ISSN 1981-0601 \\
\hline
\end{tabular}

A abordagem da análise de gênero aplicada é um desdobramento recente da análise do discurso e possui três orientações:

1- Orientação lingüística: tinha como preocupação alguma forma de registro ou análise estilística. $O$ autor critica esse tipo de análise por acreditar que a mesma contribui pouco no entendimento da natureza dos gêneros;

2- Orientação sociológica: nessa orientação o centro da atenção são os processos sociais que envolvem o texto, tornando-o dinâmico e incompleto;

3- Orientação psicológica: revela dois elementos importantes: a estrutura cognitiva (relacionada às áreas de investigação) e os aspectos táticos da descrição de gênero (prioriza as escolhas individuais do escritor). Os aspectos táticos da descrição de gênero, chamados de estratégias se dividem em duas formas: estratégias não-discriminativas (não mudam o propósito comunicativo do gênero) e estratégias discriminativas (modificam a natureza do gênero).

O autor apresenta sete passos de investigação que permitem compreender um gênero:

1- Inserção de um dado gênero-texto num contexto situacional;

2- Levantamento da literatura existente;

3- Refinamento da análise situacional/contextual;

4-Seleção do corpus;

5- Estudo do contexto institucional;

6- Níveis de análise lingüística;

7- coleta de informações dos especialistas que usam um dado gênero.

Bhatia (1993) apresenta sugestões ao pesquisador para poder explorar ao máximo a cooperação com o informante: saber o que quer; saber perguntar; reformular as perguntas, quando necessário; registrar os dados; e ver o parecer de outro informante. Para o autor o gênero é um evento comunicativo socioculturalmente dependente e se torna eficaz quando assegura o sucesso pragmático nos contextos profissionais nos quais é usado. $O$ autor avalia as limitações e as vantagens do modelo de análise dos gêneros e confirma a sua 


\begin{tabular}{|l|l|l|l|l|l|l|}
\hline InterteXto & Uberaba & UFTM & $\begin{array}{l}\text { v. 3 } \\
\text { n. } 1\end{array}$ & p. 61-84 & 2010 - jan. / jun. & ISSN 1981-0601 \\
\hline
\end{tabular}

eficácia. Ele dá exemplo do papel que o propósito comunicativo desempenha na identificação de gêneros utilizando atividades lingüísticas de duas áreas diferentes: promoção de vendas e auto-propaganda, conclui que há aspectos comuns nos dois tipos de documentos, portanto, deveriam ser considerados exemplos de gêneros promocionais.

\section{Estudo de gêneros no Brasil}

\subsection{Marcuschi: gêneros textuais}

Marcuschi (2002) afirma serem os gêneros textuais resultado das práticas culturais de cada época que surgem com a mesma facilidade que desaparecem, mostrando ao mesmo tempo a inadequação em defini-los somente pela forma. Os elementos definidores dos gêneros textuais são os aspectos sócio-comunicativos e funcionais da própria língua, como atividade social, histórica e cognitiva. Para o autor, os gêneros textuais são práticas sócio-históricas, ao mesmo tempo em que são definidos pelos fenômenos históricos e sócio-culturais. Enquanto entidades sócio-discursivas são maleáveis, dinâmicos e plásticos; originam-se nas necessidades e atividades sócio-culturais.

O autor analisa o contexto histórico dos estudos de gêneros, os quais remontam a Platão e Aristóteles. Os gêneros saíram da fronteira da retórica e da poética e passaram para o domínio da lingüística, nas perspectivas discursivas. Historicamente, nasceram orais e limitados; em uma segunda fase (por volta do século VII a.C.) multiplicaram-se devido ao surgimento da escrita; em uma terceira fase (a partir do século $X V$ ), teve grande expansão com o florescimento da escrita. $\mathrm{Na}$ fase atual, há uma explosão de novos gêneros e novas formas de comunicação oral e escrita.

O estudo dos gêneros textuais não é novo e, no Ocidente, já tem pelo menos vinte e cinco séculos, se considerarmos que sua observação sistemática iniciou-se em Platão. $O$ que hoje se tem é uma nova visão do mesmo tema. Seria gritante ingenuidade histórica imaginar que foi nos últimos decênios do 


\begin{tabular}{|l|l|l|l|l|l|l|}
\hline InterteXto & Uberaba & UFTM & $\begin{array}{l}\text { v. 3 } \\
\text { n. 1 }\end{array}$ & p. 61-84 & 2010 - jan. / jun. & ISSN 1981-0601 \\
\hline
\end{tabular}

século $X X$ que se descobriu e iniciou o estudo dos gêneros textuais (MARCUSCHI, 2008, p. 147).

Para o autor, hoje se tem novos gêneros em velhas bases, pois o uso intensivo das novas tecnologias, atualmente, tem proporcionado o surgimento de novos gêneros textuais. $E$, mesmo que as novas formas discursivas estejam relacionadas às novas tecnologias (teleconferências, cartas eletrônicas etc.) os novos gêneros têm por base gêneros já existentes.

Marcuschi (2008) faz uma distinção entre tipo textual, gênero textual e domínio discursivo. Tipo textual é a construção teórica definida pela natureza lingüística de sua composição (aspectos lexicais, sintáticos, etc.). Exemplos: narração, argumentação, exposição, descrição, injunção:

Tipo textual designa uma espécie de construção teórica (em geral uma seqüência subjacente aos textos) definida pela natureza lingüística de sua composição (aspectos lexicais, sintáticos, tempos verbais, relações lógicas, estilo). O tipo caracteriza-se muito mais como seqüências lingüísticas (seqüências retóricas) do que como textos materializados; a rigor, são modos textuais (MARCUSCHI, 2008, p. 154).

Já o gênero textual é composto de realizações lingüísticas definidas por propriedades sócio-comunicativas. Exemplos: carta comercial, bula de remédio, aula expositiva, etc.

Gênero textual refere os textos materializados em situações comunicativas recorrentes. Os gêneros textuais são os textos que encontramos em nossa vida diária e que apresentam padrões sociocomunicativos característicos definidos por composições funcionais, objetivos enunciativos e estilos concretamente realizados na integração de forças históricas, sociais, institucionais e técnicas (MARCUSCHI, 2008, p. 155).

O autor define domínio discursivo como uma esfera ou instância de produção discursiva ou de atividade humana. Sendo assim, não são textos nem discursos, mas propiciam o surgimento de discursos bastante específicos, pois constituem práticas discursivas em que são identificados um conjunto de gêneros textuais. 


\begin{tabular}{|l|l|l|l|l|l|l|}
\hline InterteXto & Uberaba & UFTM & $\begin{array}{l}\text { v. 3 } \\
\text { n. 1 }\end{array}$ & p. 61-84 & 2010 - jan. / jun. & ISSN 1981-0601 \\
\hline
\end{tabular}

Domínio discursivo constitui muito mais uma "esfera da atividade humana" no sentido bakhtiniano do termo do que princípio de classificação de textos e indica instâncias discursivas (por exemplo: discurso jurídico, discurso jornalístico, discurso religioso, etc.). Não abrange um gênero em particular, mas dá origem a vários deles, já que os gêneros são institucionalmente marcados (MARCUSCHI, 2008, p. 155).

Para o autor, o estudo de gêneros textuais deve ser feito de maneira interdisciplinar levando em consideração o funcionamento da língua e as atividades culturais e sociais envolvidas no processo. Marcuschi deixa claro nas suas colocações que os gêneros são mais amplos que os tipos textuais e que ambos são fruto de cada época histórica e de cada contexto cultural, pois são formas expressivas da humanidade.

\section{Considerações Finais}

A abordagem dos gêneros do discurso poderia permanecer no campo da lingüística textual caso fosse uma perspectiva autônoma e diferente da Teoria da Literatura clássica, porém, a abrangência ilimitada do conceito de "Gêneros Discursivos" apresenta uma vasta gama de elementos como sendo "gêneros" quando os mesmos já se encontram inclusos nas categorias: gênero, subgênero e espécies, da teoria literária tradicional comprometendo, com isso, a percepção da obra de arte literária como fenômeno complexo em cujo âmago se encontram os elementos estético, epistemológico e ético como base do discurso literário. Encontram-se posicionamentos em que se afirma que "a expressão 'gênero' sempre esteve, na tradição ocidental, especialmente ligada aos gêneros literários, mas já não está mais assim" (MARCUSCHI, 2002, p. 29). O Professor da Universidade Federal de Pernambuco faz tal colocação tendo como base a seguinte idéia:

Indeed today, genre is quite easily used to refer to a distinctive category of discourse of any type, spoken or written, with or 


\begin{tabular}{|l|l|l|l|l|l|l|}
\hline InterteXto & Uberaba & UFTM & $\begin{array}{l}\text { v. 3 } \\
\text { n. } 1\end{array}$ & p. 61-84 & 2010 - jan. / jun. & ISSN 1981-0601 \\
\hline
\end{tabular}

without literary aspirations ${ }^{5}$ (Swales, 1990, p. 33).

Partindo da idéia anterior de Swales e para melhor entender a noção de Gêneros Discursivos é preciso estabelecer a distinção entre "tipo" e "gênero" textual: “Usamos a expressão 'tipo textual' para designar uma espécie de construção teórica definida pela natureza lingüística de sua composição (aspectos lexicais, sintáticos, tempos verbais, relações lógicas). Em geral, os tipos textuais abrangem cerca de meia dúzia de categorias conhecidas como: narração, argumentação, exposição, descrição, injunção" (MARCUSCHI, 2002, p. 22). Todavia, quando o referido autor coloca a narração como tipo textual, a teoria literária clássica apresenta a narrativa como uma das espécies literárias; a exposição tem seu equivalente na prosa de composição expositiva; a argumentação encontra-se nas espécies oratória e didática; a descrição está presente nas espécies narrativa, oratória, epistolar, didática, etc.; e o tipo textual de injunção (ordem formal) tem correspondência com os gêneros especiais em forma prosaica, de conteúdo objetivo, composição expositiva, encontrando-se de modo particular nas espécies oratória (sacra ou profana), epistolar (didática ou doutrinal), e na espécie didática.

O segundo conceito apresentado por Marcuschi refere-se ao gênero textual como "uma noção propositalmente vaga para referir os textos materializados que encontramos em nossa vida diária e que apresentam características sócio-comunicativas definidas por conteúdos, propriedades funcionais, estilo e composição característica" (MARCUSCHI, 2002, p. 22/3). Não há lugar a dúvidas que a carta comercial, carta pessoal, carta eletrônica não são três gêneros distintos como propõe Marcuschi, mas expressões do único gênero epistolar de conteúdo variável, composição expositiva e suportes diversos; a aula expositiva, conferência, reportagem jornalística, piadas, reunião de condomínio e aulas virtuais igualmente não constituem gêneros diferentes, mas manifestações do gênero oratório de conteúdo sacro ou

\footnotetext{
${ }^{5}$ Hoje, gênero é facilmente usado para referir uma categoria de discurso de qualquer tipo, falado ou escrito, com ou sem aspirações literárias.
} 


\begin{tabular}{|l|l|l|l|l|l|l|}
\hline InterteXto & Uberaba & UFTM & $\begin{array}{l}\text { v. 3 } \\
\text { n. } 1\end{array}$ & p. 61-84 & 2010 - jan. / jun. & ISSN 1981-0601 \\
\hline
\end{tabular}

profano e finalidade acadêmica, circunstancial, política ou deliberativa, etc.; as notícias jornalísticas, receitas culinárias, bula de remédios, cardápio de restaurantes, instruções de uso, outdoor, resenhas, edital de concurso, etc., não constituem gêneros autônomos, senão formas particulares do gênero didático que tem a intenção de instruir, educar, e muitas vezes, simplesmente informar. Muito embora não se possa "incluir no gênero didático (literário) um manual de Física, de Química, de Matemática, um tratado de engenharia ou de construção de pontes" (TAVARES, 1978, p. 150); as características dos gêneros literários podem, e são utilizados como gêneros discursivos em sentido lato, não precisando caracterizar formas particulares de expressão como novos gêneros conforme apresentado pelos expoentes dos "Gêneros do Discurso".

Autores ligados à Lingüística Textual contemporânea se esforçam em mostrar que "a mobilidade dos gêneros permite dizer que caminhamos para uma 'hibridização' ou 'mesclagem' de gêneros de tal ordem que podemos chegar a uma situação em que não mais haja 'categorias de gêneros puros e sim fluxos"' (MARCUSCHI, 2005, p. 25). Provavelmente, ao entender "os gêneros literários como entidades perfeitamente diferenciadas entre si, configuradas por distintos caracteres temáticos e formais, devendo o poeta mantê-los cuidadosamente separados, de modo a evitar, por exemplo, qualquer hibridismo entre os gêneros cômico e o gênero trágico" (SILVA, 1996, p. 347); Horácio intuíra um processo de degenerescência por perda de identidade dos gêneros literários. A teoria horaciana dos gêneros pode ser aceita dentro de uma visão exclusiva dos "gêneros fundamentais", porém, ao considerar os "gêneros especiais" com as diversas formas, conteúdos, modos de composição, espécies e formas poéticas, torna-se preciso flexibilizar a concepção de gênero apresentada por Horácio, sem chegar à excessiva licença referente à classificação dos gêneros discursivos que se manifesta no atual contexto dos "gêneros discursivos".

Ao afirmar que: "os gêneros não são entidades formais, mas sim 


\begin{tabular}{|l|l|l|l|l|l|l|}
\hline InterteXto & Uberaba & UFTM & $\begin{array}{l}\text { v. 3 } \\
\text { n. } 1\end{array}$ & p. 61-84 & 2010 - jan. / jun. & ISSN 1981-0601 \\
\hline
\end{tabular}

entidades comunicativas. Gêneros são formas verbais de ação social relativamente estáveis realizadas em textos situados em comunidades de práticas sociais e em domínios discursivos específicos" (MARCUSCHI, 2002, p. 25); é preciso observar que se a "estabilidade" fizesse referência a ações sociais (no plural) seria válida a assertiva porque não entraria em contradição com a noção de mobilidade dos gêneros. No entanto, como se fala de gênero como "formas verbais estáveis", surge uma incoerência entre o expresso por Marcuschi, na referência anterior, e o conceito apresentado pelo mesmo autor quando se refere à ideia exposta por Gunther Kress, de hibridização e mesclagem dos gêneros fruto da mobilidade dos mesmos.

A análise da estética literária, no contexto atual, precisa acompanhar o debate sobre os gêneros discursivos por oposição aos gêneros literários, haja vista que os primeiros valorizam a linguagem enquanto ato comunicativo de uma determinada comunidade; entanto que os segundos são deixados no esquecimento descuidando dos processos de produção discursiva de ordem universal. Segundo Swales (1990) o critério prototípico para a identidade do gênero opera como principal determinante da tarefa da linguagem que tem no propósito comunicativo o elo que define as atividades da linguagem de uma comunidade discursiva.

No entanto, Bakhtin (2003) lembra que Humboldt, sem negar a função comunicativa da linguagem, procurou colocá-la em segundo plano; promovendo ao primeiro plano a função da forma do pensamento, independente da comunicação, mostrando, assim, a língua como uma condição indispensável do pensamento humano: não há pensamento fora de formas simbólicas que representem o mundo, assim como o mundo é apreendido e vivenciado mediante processos de linguagem. Como é fácil perceber, os dois teóricos dos gêneros do discurso se encontram em patamares diferentes e não contraditórios, pois se a língua se encontra na base da formação do pensamento, este é exteriorizado nos processos de socialização dirigindo-se para a função comunicativa. 


\begin{tabular}{|l|l|l|l|l|l|l|}
\hline InterteXto & Uberaba & UFTM & $\begin{array}{l}\text { v. 3 } \\
\text { n. } 1\end{array}$ & p. 61-84 & 2010 - jan. / jun. & ISSN 1981-0601 \\
\hline
\end{tabular}

\section{Referências}

BAKHTIN, Mikhail Mikhilovitch. Estética da criação verbal. (tradução feita a partir do francês por Maria Ermantina Galvão G. Pereira). 2 ed. São Paulo: Martins Fontes, 1997.

BAKHTIN, Mikhail. Estética da criação verbal. (tradução do russo por Paulo Bezerra). 4 ed. São Paulo: Martins Fontes, 2003.

BASÍLIO, Margarida. Teoria lexical. 8 ed. São Paulo: Ática, 2007.

BAZERMAN, Charles. Genros textuais, tipificação e interação. In: Dionísio, A. e Hoffnagel, J. C. São Paulo: Cortez, 2004.

BHATIA, V. K. (1993). Analysing genre: language use in profissional settings. London/New York: Longman, 1993.

BIASI-RODRIGUES, Bernadete. A diversidade de gêneros textuais na escola: um novo modismo? Revista Perspectiva, Florianópolis: Ed. Da UFSC, v.20, n.1,p. 49-64, jan./jun./2002.

BIASI-RODRIGUES, Bernadete. (2004). Tratamento dos gêneros textuais na escola. In: CAVALCANTE, Mônica Magalhães \& BRITO, Mariza Angélica Paiva (orgs.). Gêneros textuais e referenciação. Fortaleza, Protexto UFC. CD-Rom. BIASI-RODRIGUES, Bernadete. (2004). Diferentes abordagens teóricas sobre gêneros textuais e suas implicações para o ensino. IN: CAVALCANTE, Mônica Magalhães \& BRITO, Mariza Angélica Paiva (orgs.) Gêneros textuais e referenciação. Fortaleza, Protexto UFC. CD_Rom. ISBN 85-904864-1-9.

CARVALHO, G. de (2005). Gênero como ação social em Miller e Bazerman: o conceito, uma sugestão metodológica e um exemplo de aplicação. In: MEURER, J. L.; BONINI, A. \& MOTTA-ROTH, D. (orgs). Gêneros - teorias, métodos, debates. São Paulo: Parábola, 2005.

BONINI, Adair. Ensino de gêneros textuais: a questão das escolhas teóricas e metodológicas. Trabalhos em Lingüística Aplicada, Campinas, (37): 1108,jan./jun.2001.

BRANDÃO. H. H. N.. Texto, Gêneros do Discurso e Ensino. In. 


\begin{tabular}{|l|l|l|l|l|l|l|}
\hline InterteXto & Uberaba & UFTM & $\begin{array}{l}\text { v. 3 } \\
\text { n. } 1\end{array}$ & p. 61-84 & 2010 - jan. / jun. & ISSN 1981-0601 \\
\hline
\end{tabular}

BRONCKART, J. P. Atividades de linguagem, textos e discursos. São Paulo: EDUC, 1999.

FÁVERO, Leonor. Coesão e coerência textuais. 11.ed. São Paulo: Ática, 2006.

MARCUSCHI, Luiz Antônio. Gêneros textuais: definição e funcionalidade. In: DIONÍSIO, A. P., MACHADO, A. N. BEZERRA, M. A. (orgs). Gêneros textuais \& ensino. Rio de Janeiro: Lucerna, 2002. p. 19-36.

MARCUSCHI, Luiz Antônio. Produção textual, análise de gêneros e compreensão. São Paulo: Parábola, 2008.

MARCUSCHI, Luiz Antonio. Da fala para a escrita: atividades de retextualização. 8.ed. São Paulo: Cortez, 2007.

MILLER, C. R. (1994a) Genere as social action. In: FREEDMAN, A \& MEDWAY, P. (eds.). Genre and the new rhetoric. Taylor \& Francis.

ORLANDI, Eni Puccinelli. Discurso e texto: formulação e circulação dos sentidos. Campinas, SP: Pontes, $2^{\mathrm{a}}$ edição, 2005.

RAMIRES, Vicentina (2005). Panorama dos estudos sobre gêneros textuais. In: Investigações Lingüísticas e Teoria Literária. Universidade Federal de Pernambuco: Vol. 18, $n^{\circ}$ 2, julho.

SILVA, Victor Manuel de Aguiar e. Teoria da Literatura. 8 ed. Coimbra: Almadina, 1996.

SWALES, John. M. Genre Analysis: English in academic and research settings. Cambridge: Cambridge University Press, 1990.

TAVARES, Hênio. Teoria Literária. 6 ed. Belo Horizonte: Itatiaia, 1978. 